\title{
Acompanhamento terapêutico: um dispositivo de desafios
}

\author{
Therapeutic follow-up: a dispositive of challenges
}

Carla Lavarda Concentino Caetano ${ }^{[a]}$, Andrea Cristina Coelho Scisleski ${ }^{[b]}$

\footnotetext{
${ }^{[a]}$ Mestranda em Psicologia pela Universidade Católica Dom Bosco, Campo Grande, MS - Brasil, e-mail: cacaconcentino@hotmail. com

${ }^{[b]}$ Doutora em Psicologia e professora do Programa de Pós-graduação em Psicologia da Universidade Católica Dom Bosco, Campo Grande, MS - Brasil,

Recebido: 19/04/2013 Received: 04/19/2013
}

Aprovado: 29/10/2013 Approved: 10/29/2013

\section{Resumo}

Este texto é parte de um estudo de especialização em Clínica e Saúde. Trazemos questionamentos das Políticas Públicas para infância e juventude, articulando as relações entre saúde e as redes de serviço, bem como práticas da Clínica Ampliada, enfatizando a função do acompanhante terapêutico e evidenciando o Acompanhamento Terapêutico como um dispositivo clínico, capaz de produzir mudanças e atravessamentos na transversalidade do campo da Saúde Coletiva. Para isso, utilizamos uma análise do campo social partindo da história de uma criança que é tomada como problemática por diversas instituições. Também apontamos a função do acompanhante terapêutico como um catalisador entre a criança, as instituições e a cidade, problematizando os modos de relação construídos pelo viés dos saberes e verdades instauradas nesses campos de subjetivação. Com isso, entendemos que as considerações finais ou conclusões não podem ser fechadas e apontamos alguns direcionamentos e mudanças como propulsores de novas práticas em Saúde.

Palavras-chave: Saúde Coletiva. Acompanhamento Terapêutico. Clínica Ampliada.

Adolescente.

\section{Abstract}

This text is part of a study of specialization in Clinic and Health. In this article we bring questions about public policies for children and youth, articulating the relations between health and service networks as well as practices in Extended Clinic to emphasize the role of therapeutic follow-up and highlight the Therapeutic Follow-up as an efficient clinical dispositive in producing changes and crossings into the transversality of field of Collective Health. In order to do so, we used an analysis of the social field based on the story of a child who is seen as problematic by several institutions. We also pointed out the role of therapeutic follow-ups as a catalyst between the child, the institutions and the city, questioning modes of relationship built by the bias of knowledge and truths brought into these fields of subjectivity, therewith we understood that the final considerations and conclusions cannot be closed and pointed out some directions and changes to be taken as a propeller of new practices in health

Keywords: Extended clinic. Therapeutic follow-up. Collective health.

Psicol. Argum. 2014, 32(79), Supl. 2, 89-97 


\section{Introdução}

Este artigo é parte de um percurso clínico social desenvolvido na monografia de Especialização em Clinica e Saúde, construída a partir de um atendimento de uma criança tomada como problemática em um município no interior do Rio Grande do Sul (Caetano 2011). O objetivo do texto é discutir o acompanhamento terapêutico como um dispositivo clínico entre práxis da psicologia e apontar a interface na rede de atendimento de serviços das políticas públicas da infância e da juventude.

A discussão aqui reside na proposta de demonstrar práticas da Psicologia Social, enfocando as questões da saúde mental no acompanhamento terapêutico - uma forma de trabalho na saúde e no cotidiano da relação do sujeito com a cidade. Para isso, abordaremos as práticas clínicas feitas com Lucas ${ }^{1}$, um menino que encontra dificuldades de pertencimento à vida familiar e de adaptação às instituições disciplinares, sendo que sua vivência evidencia uma situação de exclusão, ainda que o menino demande uma busca por reconhecimento, conforme será visto adiante.

Cabe salientar que Lucas é visto como desajustado em seu município e é conhecido na cidade "como aquele que perturba", seja por argumentos que o tomam como doente mental, seja por discursos que o descrevem como delinquente. Apesar de ter passado por diversos lugares, os serviços que atendiam a criança - Escola, Centro de Atenção Psicossocial, Conselho Tutelar, entre outros - por vezes operavam em uma lógica que atribuía ao menino uma culpabilização individual por suas dificuldades e sem grandes preocupações em oferecer intervenções que oportunizassem senão uma resolutividade, ao menos uma amenização de alguns dos seus problemas (Caetano \& Scisleski, 2011).

Muitas vezes durante os atendimentos de Lucas percebeu-se que há certo distanciamento e rejeição das instituições para com o menino, pois em seu município diversos profissionais, tais como médicos, professores, psicólogos, policiais, entre outros, enfatizam que Lucas deve ser mantido à distância, uma vez que ele é percebido como um problema causador de diversos danos à família, ao patrimônio público e às instituições. No entanto,

${ }^{1}$ Nome fictício, criado para preservar a identidade da criança. tanto a sua família como os próprios serviços que o atenderam (e o abandonaram) não se implicam naquilo que é tomado como desajuste do menino. Isso é um elemento bastante significativo, pois o próprio Lucas passa a duvidar de si mesmo diante dos discursos acusadores que o subjetivaram como "aquele que não tem mais jeito". A questão que nos colocamos, a partir desse contexto, concerne sobre a possibilidade do Acompanhamento Terapêutico ser um dispositivo capaz de possibilitar outros efeitos na vida dos sujeitos.

Buscamos com Lucas outros modos de significação, e quem sabe algum modo de subjetivação que seja mais viável dentro desse viés de significados instaurados em nossa sociedade atual. De acordo com Foucault (2000), podemos fazer uma crítica aos modos de subjetivação contemporâneos, pois para vivermos conforme o projeto de sociedade que temos - capitalista e neoliberal - precisamos ser normalizáveis e adaptáveis às normas sociais vigentes.

Para contar a história do menino mostramos ao longo do artigo algumas cenas do cotidiano da acompanhante terapêutico (at) e de Lucas, ilustrando um pouco da vivência e da prática do acompanhamento terapêutico (AT). Destacamos a importância desse profissional na área da saúde coletiva, pois este pode ser um dispositivo de intervenção nos modos de subjetivação, já que o at objetiva oferecer outros modos de produzir relações entre sujeitos. Cabe ressaltar que Lucas é uma criança pobre, rejeitada pela mãe e cuidada eventualmente pela avó. Outro fator importante é que o menino mora em uma região central da cidade, o que é ainda mais agravante, pois por não estar na periferia, acaba ocupando um lugar de visibilidade, atingindo justamente aqueles que, diferentemente dele, são de uma classe social mais abastada economicamente.

\section{Acompanhante Terapêutico - fazendo conexões pela cidade}

Por meio da prática do Acompanhamento Terapêutico (AT) busca-se junto do sujeito outra forma de circular pela cidade, trabalhando as vivências com Lucas a partir de sua circulação, discutindo suas experiências de exclusão no social e aquelas que lhe marcaram afetivamente como ocasiões de diversão e de acolhimento. De acordo com Porto e 
Sereno (1991), o acompanhante terapêutico (at) opera como um conector a realidade de urbe e aos espaços da cidade que o exclui, atuando na construção do resgate da capacidade em sua própria confiança.

Quanto à história dessa prática, Mauer e Resnizky (1987) trazem relatos de experiências de trabalho de 1971 sobre terapias de abordagem múltipla com "doentes" severamente perturbados que procuravam as consultas geralmente em momentos de crise, e de um modo geral, se opunham a outras formas de psicoterapia ou rejeitavam a formas convencionais de tratamento. A modalidade de AT surgiu na Argentina, com o nome de "amigo qualificado", para atender necessidades da pessoa, além do âmbito da clínica tradicional, o de consultório. O "dispositivo de intervenção do Acompanhamento Terapêutico" (Iamin \& Ramos, 2013 p.3), inicia-se na década de 70 , por meio de um intercâmbio cultural e científico entre o Brasil e a Argentina.

Pelliccioli e Guareschi (2004) afirmam que o AT surgiu no Brasil como modalidade de intervenção pela influência de campos aparentemente distintos: a prática clínica, os movimentos da reforma psiquiátrica e o surgimento das comunidades terapêuticas. Os autores ainda propõem uma discussão sobre a emergência do trabalhador, acompanhante terapêutico $(a t)$ na rede pública por meio da análise e entrevistas com trabalhadores dessa modalidade, entre outras questões históricas que incluem o contexto dessa prática, entendendo a passagem de tal modalidade de trabalho, antes tomada como uma prática complementar, à efetivação de estratégias que fossem fundamentais à implementação da Reforma Psiquiátrica.

Já sobre a prática de trabalho, Palombini (2008) traz considerações sobre a clínica do AT na psicose. Porém, pensamos que podemos alargar essa dimensão, pois se pode incluir nesta perspectiva aquele que não se enquadra ao padrão de uma norma de um modo geral. Ou seja, o "desajustado" de hoje é o "psicótico" de ontem no contexto da Reforma Psiquiátrica. No entanto, para Palombini (2008), o AT implica em um deslocamento do espaço de atuação dos profissionais, pois o campo de trabalho em saúde mental provoca trocas sociais na comunidade local. Com isso, para a autora, abandonam-se as paredes e clausuras do hospital ou do conforto da clínica em sua esfera usual e se usa a rua, a praça, a vizinhança e a cidade, como espaço para praticar a clínica.
0 acompanhamento terapêutico é uma expedição pioneira a uma cidade desconhecida a que se vai às vezes como reféns, às vezes como invasores, outras vezes como passeantes. É uma expedição a dois na qual se experimenta caminhos até os limites permitidos pelo entorno (Porto e Sereno 1991 p.26).

Para Camargo (1991), o acompanhante terapêutico (at) funciona como um agente de saúde da vida cotidiana, como um catalisador das potencialidades do sujeito, compromissado com mecanismos de apropriação e reapropriação dos sentidos e das percepções, visando a inserção da pessoa na trama social. Nessas tramas do social e das relações em que se estabelece na vida cotidiana, o at caminha lado a lado, muitas vezes se "emprestando" ao acompanhado para lhe auxiliar em seus fluxos e suas decisões da vida cotidiana.

Na situação de Lucas se enfatiza como as instituições são fechadas, tais como a escola, o conselho tutelar, entre outros, uma vez que tratam o sujeito a partir de verdades produzidas nesse contexto de fechamento, não levando em conta as condições de existência da pessoa que essas mesmas instituições frequentemente excluem. Diante a isso, entendemos que a atuação do at é uma pequena parte dentro de um todo complexo que envolve um contexto familiar, social, jurídico e institucional que, por intermédio dessa modalidade de trabalho, busca abrir portas, desconstruir verdades e construir novos caminhos de existência com sujeito na construção de novos vínculos.

\section{Circulando pela cidade: o fórum e a relação com 0 judiciário}

No início do período de atendimento Lucas tinha dez anos e apresentava um processo jurídico com duas pastas imensas, as quais constam negligência da família, passagens por algumas escolas e perambulação por diversos médicos da cidade e do estado, inclusive com duas passagens de internação em hospital psiquiátrico fora de seu município. A cada vez que voltava de uma consulta, o menino recebia um novo diagnóstico, indo desde hiperatividade a transtorno de conduta, e com o diagnóstico "atualizado" surgia também uma nova proposta medicamentosa. No entanto, por sua insubordinação ao que é tido como normalidade, apesar das inúmeras

Psicol. Argum. 2014, 32(79), Supl. 2, 89-97 
medicações, Lucas escapou ao controle pela ação médica. Então, desse modo, Lucas é um sujeito que vive à mercê de tudo, uma vez que não consegue ser enquadrado.

Foucault (2007) ao falar sobre a função do hospital psiquiátrico do século XIX, afirma que este exerce um lugar de diagnóstico e classificação, em que as espécies de doenças são classificadas, lugar onde o médico é capaz de falar a verdade sobre a doença, ou o juiz a do ato infracional, ou ainda a instituição de saber que determina aquele espaço de aprisionamento e é capaz de dizer a verdade sobre o sujeito.

0 que parece é que de fato a maior dificuldade de Lucas é justamente a inscrição em alguns espaços, pelo fato de que não é "dócil" e tocável por esses mecanismos disciplinares - "a disciplina é o conjunto de técnicas pelas quais os sistemas de poder vão ter por alvo e resultado os indivíduos em sua singularidade" (Foucault, 2007 p.62). A situação de Lucas se agrava pelo fato de que não é diagnosticado nem como doente, nem como delinquente dentro do modelo médico vigente. Consideramos que os diagnósticos permitem uma captura do sujeito pelo saber, permitindo uma medicalização que tenha um efeito específico para a doença, ou no caso de delinquente, uma medida de julgamento e condenação.

Outra vez, por meio de uma intervenção, nos foi permitido que conhecêssemos o seu processo no fórum. Dessa maneira, conseguimos ter um maior conhecimento da história da "carreira" e da vida de Lucas. Para falar dessa carreira, utilizamos o termo de Goffman (2001), já que a entendemos como qualquer trajetória cursada durante a vida, em termos de percursos, mesmo que de internação, como utiliza o referenciado autor.

Podemos ver que há um emaranhado de fios que constituem Lucas de um modo errante e dissociado, sendo assim: como pensar em constituição subjetiva nesses caminhos de uma produção do doente mental? Pode-se entender que nessa construção da pessoa qualquer potencialidade positiva pode ser esquecida, considerando somente alguns resultados singulares negativos?

Há uma página do processo que possui a cópia de uma ata da escola que Lucas tentou frequentar, mas não conseguiu, e em seguida o relato da avó sobre o mesmo acontecimento. Na ata constava que o menino tentou entrar no colégio, porém, quando impedido, passou a atirar pedras nas janelas da escola.
Segundo a avó do menino, havia uma liberação do juiz para que a criança se matriculasse na escola e os dirigentes da escola sabiam disto. Porém, Lucas foi à escola sem os documentos de liberação da matrícula, que ainda não estavam prontos, e como não o deixam entrar, ele começou a atirar pedras. Desse modo, perguntamos: o comportamento de quem é inadequado? O que identificamos é a culpabilização do menino, exclusiva e individualmente.

Apesar das dificuldades, o fórum é um lugar onde tivemos um pouco de acesso e, segundo a avó de Lucas, as autoridades já percebem algumas pequenas mudanças, tal como evidenciada em uma fala do promotor em uma audiência enquanto Lucas brincava com a prima: "Olha aí, esta criança não precisa de internação, precisa sim de escola, olha ele brincando, ou ainda em uma conversa com o juiz sobre a história de vida de Lucas e o histórico de abandono por diversas instituições, que resultou em um pedido de avaliação para encaminhá-lo à escola.

Pensa-se na necessidade de levar as coisas para outra instância, como solicitar o Conselho Tutelar, o promotor, o juiz, a polícia e todas essas instâncias nas quais a lei fala por si de um modo extremamente externo, vindo do "fora". Ainda que ocorra a passos vagarosos e mesmo que muitas vezes se apele a uma intervenção do judiciário, já que se trata de uma busca da proteção de direitos da criança, ressaltamos que o AT permite construir alguma outra forma de relação com as instituições, inclusive a família que, no caso de Lucas, já o abandonou, pois sua mãe o entregou aos cuidados da avó.

Entender o processo como "currículo" nos termos de Goffman, que constitui uma carreira moral, uma vez que vimos que Lucas possui um currículo imenso - duas pastas cheias de histórias que sempre culpabilizam o garoto - nos foi permitido tentar quebrar uma sequência linear e proporcionar outros rumos em sua "carreira", tarefa é bastante complexa e difícil, conforme é relatado neste texto.

Dessa maneira, podemos perceber que o AT trata de práticas de outra construção social, que busca a inserção do sujeito, não pela sua docilização, mas pelo trabalho de criar com o sujeito outras formas de habitar a cidade, e nesse percorrer, indicar para os outros que coabitam a cidade, outros olhares para com ele. No caso de Lucas, ao falarmos de uma criança que possui direitos, pensamos que o garoto deve ter acesso aos serviços educacionais, de saúde e outras instituições de inclusão. Sabemos aqui 
que tratamos de uma criança, com dificuldade de inscrever suas vontades, assim como sabe-se que a sociedade atual se constrói cada vez mais com práticas de esquadrinhamento da população, e nesse movimento de esquadrinhar, produz marginalidade de muitos. Diante dessa colocação, questionamos: o que estamos produzindo enquanto sociedade, com tantos discursos de inclusão e práticas de exclusão?

\section{Quebrando barreiras - modificando discursos}

Contar a história de uma criança que tem experiências de destituição de espaços de circulação e, por conseguinte, de existência, que ao mesmo tempo vive diante da produção de uma infância que é propagandeada pela mídia e pela nossa sociedade capitalista e moderna como "normal", ou seja, consumidora, coloca Lucas em uma posição, por vezes, marginal.

Em uma análise sobre as políticas públicas para a infância no Brasil, Faleiros (2009) afirma que a criança pobre se torna caso de polícia. Tanto o primeiro Código de Menores de 1927, o qual funciona com um caráter higienista e defensor de práticas de "limpeza social", quanto seu sucessor, o segundo Código de Menores de 1979, preconizador da doutrina da situação irregular, postulavam uma intervenção sobre a criança pobre, chamada e tratada de "menor". Em ambas as perspectivas, a criança deveria ser retirada das ruas no intuito de proteção à sociedade, culpabilizando a própria criança e a "família desestruturada" de onde provinha por sua inadequação, por praticar vadiagem e por perambular pelas ruas.

Lucas é uma criança, porém, não podemos dizer que ele tem uma infância tal como é colorida pela mídia, na qual a pessoa "goza os seus direitos", responsável pelo futuro do país e um futuro cidadão, que obtém reconhecimentos pelos seus feitos e é atendida em suas necessidades. Lucas parece ser a criança que deve ser alvo das políticas de repressão, tais como a punição policial, internações psiquiátricas, entre outras.

Vivemos em uma sociedade permeada por diagnósticos e formas de normatização que usam de critérios de classificação para diferenciar pessoas - e que muito pouco discute ou propõe outras formas de atuação junto dos ditos "anormais". Isso se encontra ainda hoje em alguns lugares, ou em algumas instituições, especialmente na escola (Faleiros, 2009).
Não estamos procurando determinar qual a parcela de responsabilidade moral, isso é problema dos juristas e jurados... Procuramos simplesmente saber se do ponto de vista médico-legal suas anomalias de caráter tem origem patológica, se realizam um distúrbio mental suficiente para atingir a responsabilidade penal (Foucault, 2001 p. 6.).

Ao falarmos sobre Lucas, falamos de uma criança que sente vontade de existir e de pertencer, mas não tem força sozinha, pois não se trata de algo que dependa apenas de sua força de vontade. Considerando que essa criança já tem seu "currículo" circulando com todos seus traços de infração, quando tenta falar por si, traz marcas da sua estigmatização identitária (Goffman, 1988), discursos e condições de existência que esse menino carrega como uma "tatuagem", como marcas gravadas em seu corpo. Na busca de construir qualquer outro "desenho existencial", as dificuldades que Lucas encontra são tantas que ele mesmo se culpabili$\mathrm{za}$, acreditando às vezes que não "tem mais jeito". Apesar das adversidades, e talvez justamente por causa delas, outros dispositivos clínicos são importantes, uma vez que colocamo-nos contra uma política de existência enclausurada, não mais necessariamente dentro de manicômios (Scisleski, Maraschin \& Silva, 2008), mas a favor de itinerários recorrentes de exclusão, e pensamos que o AT pode ser uma estratégia de abertura a outras formas de circular, habitar e existir na contemporaneidade.

Certa vez a at estava em seu consultório (pois às vezes atendia eventualmente também nesta modalidade), e excepcionalmente combinou de atender Lucas ali. Lucas já estava aguardando para ser atendido na sala de espera. Quando termina o atendimento anterior ao dele, Lucas estava observando as pessoas que saiam da sala, constatando que se tratava de outro menino, usando uma mochila, com a mãe e a irmã à sua espera. Quando os mesmos saem da clínica Lucas faz uma constatação com uma expressão de tristeza: "ele vai na escola!" E nós pensamos: o que o faz tão diferente das outras crianças? Por que Lucas não tem os mesmos direitos?

\section{Abrindo caminhos - construções em saúde}

Nos campos de atuação em saúde, novos modos de fazer a psicologia vêm sendo gestados, como é

Psicol. Argum. 2014, 32(79), Supl. 2, 89-97 
o caso do AT, especialmente porque esse dispositivo pode se tornar uma estratégia de abertura e de inclusão, já que temos uma complexa configuração social e política que propõe incessantemente práticas clínicas fechadas e tradicionais.

O AT consiste em colocar práticas modificadoras que pretendem a perspectiva de integralidade do sujeito, junto a uma série de outros fatores socais e históricos que permitem diferentes modos de atuação em clínica ampliada, práticas que buscam conhecer o sujeito em sua inteireza e, diante disso, entendemos a necessidade de quebrar barreiras hegemônicas da sociedade e do entendimento do sujeito, considerando que a pessoa vive em processo de construção continuo, com diferentes vontades e "verdades".

Nem tudo é verdadeiro; mas em todo lugar e todo momento existe uma verdade a ser dita e a ser vista, uma verdade talvez adormecida, mas que, no entanto esta somente a espera de nosso olhar para aparecer, à espera de nossa mão para ser desvelada. (Foucault, 2007 p.65).

Assim, coloca-se em questão também a atuação desses outros campos e suas formas de ação com os ditos "loucos" ou "delinquentes", agindo sobre as "verdades" e "saberes" das instituições e de nós, profissionais. Recordamos uma tarde que a at estava com Lucas na pracinha de brinquedos da cidade, e o guarda responsável pelo cuidado do local fala com a profissional, dizendo que Lucas ultimamente está mudando, pois há um tempo ia até o local somente para fazer arruaças com outra menina e hoje está brincando. Entendemos, desse modo, que muitas vezes é mais fácil modificar "verdades" com o guarda da pracinha, um "cidadão comum", do que com alguns profissionais que "funcionam" como agentes educadores e protetores dos direitos da criança.

Segundo Scisleski (2010), no contexto de saúde e justiça, além de percursos pelas vias da criminalidade, muitos jovens possuem um histórico de diagnósticos de distúrbios psiquiátricos ao serem encaminhados para unidades de internação.

...seja pela via do processo de patologização ou de um processo de atribuição de delitos, a trilha de individualização desses jovens esta dada: ou são doentes, ou são delinquentes, ou o que é ainda pior: são os dois ao mesmo tempo (p.294).
Diante de tantos fatos, podemos dizer que Lucas é "apto" a ser um adolescente em conflito com a lei, não por sua "personalidade" ou qualquer outra justificativa de cunho psicológico essencialista, mas pelo seu "currículo" produzido pela forma com que é tratado pelas instâncias que o atendem, ou melhor, que o abandonam. Atualmente, Lucas está internado em uma unidade da Fundação de Atendimento Socioeducativo no Rio Grande do Sul (FASE-RS). Cabe ressaltar que Lucas sofria de maus tratos da família, entre eles agressões físicas e verbais. Lucas agora tem doze anos e ao longo de sua vida já passou por diversas internações psiquiátricas. No entanto, o que conseguimos construir junto dele é algo que o transforma, transforma o at e produz alguns pequenos efeitos nas instituições, na família, na cidade e em muitos destes lugares que chamamos no desenvolvimento do trabalho de campo.

Birman (1999) enfatiza a pluralidade do conceito de saúde, na medida em que pode ser empregado em diversos sentidos e contextos sociais e históricos. Para o autor, a saúde é apresentada como uma palavra que pode se inscrever em diversos registros de experiência e, assim, torna-se múltipla e marcada por diversos significados.

Ressaltamos que para a mudança e delineamento de um modelo de atenção em saúde é necessária uma corresponsabilização de todos os atores sociais implicados neste campo de atuação que são, ao mesmo tempo, políticos, sociais e de trabalho (Onocko \& Campos, 2006). Consideramos que a atuação em saúde no social pode acontecer por meio de trocas e construções e, com isso, buscamos fazer das práticas um campo de construção, em que as "verdades" e "saberes" se modificam e se entrecruzam, fazendo conexões o tempo todo, práticas terapêuticas em clínica ampliada que permitem atuar junto ao sujeito, partindo de seu contexto.

Nossa atuação é uma pequena parte dentro de um cenário social que vem se modificando ao longo dos anos no Brasil. Demonstramos nesse percurso um modelo de atuação no campo social com a implicação das diversas esferas do governo e seus modos de gestão. No entanto, encontramos dificuldades de trabalhar com profissionais e com sociedade no que diz respeito às diferenças e de modificar modelos já instaurados sobre determinadas formas de ver o sujeito e sua saúde e de percebê-lo em sua integralidade. 
Para que seja possível pensar a pessoa em sua inteireza há a ideia de trabalhar em rede com a perspectiva de que os diversos atores sociais possam estar atuando em conjunto e que, se articulando entre si, seus saberes possam estar olhando o sujeito em sua integralidade aceitando a transversalidade desse trabalho. De acordo com Pereira (2008), esse tipo de trabalho implica um sentido amplo à construção e a elaboração de conhecimento à elaboração de um saber em que não se privilegia rigidamente categorias conceituais, pessoais, "status", procedimentos disciplinares, especializações, instituições ou lugares específicos de saber.

Com isso, ao dizer um pouco de cada lugar e de suas obrigações, enquanto presença de Estado, e culpabilizar as instituições seria mais uma vez trabalhar com "o certo e o errado", o que traria dicotomia ao nosso trabalho. Sendo assim, tentamos demonstrar os espaços de circulação da pessoa como processos em construção e não como formas acabadas de existência, mesmo que percebamos forças que fazem movimentos de sujeição e perpetuem lugares exclusão.

Conhecendo a história de Lucas, começamos a perceber e saber por meio dele que a criança tinha como amigos alguns adolescentes que se apresentam como "marginais" na cidade. Em conversas com o garoto, ele relata que durante a noite gosta de brincar e para isso ele e seus amigos quebram vidros e ligam para a polícia - segundo ele, é divertido incomodar a polícia. Desse modo, podemos perceber que para Lucas é uma brincadeira, porém a polícia, com o poder que lhe é conferido, deve punir aquele que a afronta de tal modo, ainda que este alguém seja uma criança.

Quando as instâncias de trabalho se entrecruzam e a verdade é entendida de diversas maneiras por distintos profissionais, percebemos modos de tratamento diferenciados, para diferentes pessoas e o que se pode ver é um antagonismo de práticas destinadas a um sujeito comum.

\section{Consideracões Finais}

Pode-se cruzar o caminho? 0 que é possível em ser acompanhante terapêutico? 0 que o Acompanhamento Terapêutico produz no campo social? Como modificar as inscrições feitas na cidade? Como concluir um trabalho que tem por fundamento ser andante?

Durante esse processo de produção, muitas vezes nos vimos incrédulas com a possibilidade de modificações e em alguns momentos foram necessárias algumas intervenções mais incisivas, tais como denuncias de negligência. Nesse momento de "conclusão" a at não faz mais parte dos atendimentos de Lucas, porém os encontros ainda acontecem eventualmente, pelo motivo do tamanho da cidade. Certo dia, a at encontrou o garoto na rua, e Lucas, contente, disse que começaria a frequentar a escola e alguns projetos de assistência social da cidade. Mas posteriormente, por meio de uma colega psicóloga que atua no mesmo município, soubemos que infelizmente tratava-se apenas de uma proposta, mas que não aconteceu efetivamente.

Embora Lucas esteja internado na FASE-RS, como já colocado antes, podemos ver que o dispositivo AT e também outros acontecimentos movimentaram algumas visões sobre suas condutas, trazendo a responsabilização das diversas esferas sociais e das redes de serviço, ilustrado pela ocorrência de uma audiência que houve no Juizado da Infância e da Juventude da cidade, na qual foram chamados representantes das secretarias de educação, saúde, assistência social, a profissional at e mesmo uma universidade para ofertar atendimentos de psicologia clínica à família do menino. Nessa audiência, foi elaborado uma espécie de plano terapêutico para quando o menino saísse da internação e ficou definida a responsabilidade de cada esfera do governo municipal, de atendimentos clínicos a Lucas e à sua família e um profissional de acompanhamento terapêutico. Mas a questão que fica é: será que isso vai acontecer?

Desse modo, vemos o acompanhamento terapêutico como dispositivo clínico e político. Nas afirmações de Palombini (2006) evidencia-se que podemos pensar sobre o efeito desse trabalho. A autora coloca que há uma incidência muito expressiva do papel do at, pois, mediante dele, surge uma maneira de possibilitar aproximações muito valiosas com as pessoas e instituições que estão inacessíveis ou não muito permeáveis aos modelos habituais de tratamento.

Porfim, podemosestabeleceroAcompanhamento Terapêutico como dispositivo clínico e que por intermédio da função do acompanhante terapêutico é possível construir conexões entre o dentro e o

Psicol. Argum. 2014, 32(79), Supl. 2, 89-97 
fora. Nesse contexto, a cidade funciona como meio e não fim. Na situação de Lucas, nossas conquistas se apresentam como efetivas não no sentido de "cura"e não mais "reincidências" do garoto, mas na possibilidade de pensar outros meios de ser e estar nos espaços sociais, tratando o sujeito com um ser em devir que caminha nas entrelinhas da rede.

Para responder a alguns questionamentos levantados neste texto, nos indagamos em relação à prática de AT com Lucas: podemos afirmar conquistas ou derrotas? Acreditamos que isso não seja possível responder à questão dessa forma, pois não é essa a proposta. 0 dispositivo do AT consiste em ter por fundamento o ser andante, em circulação, em movimento, ainda que nesse andar produzam-se paradas e mesmo algumas estagnações, que compõem o processo do próprio andar. Poder pensar sobre o itinerário que se constrói através do dispositivo do AT, em nossa experiência com Lucas, permite uma constatação: os maiores obstáculos a serem ultrapassados não se referem aos passos do menino, mas especialmente aos espaços institucionais que insistem em fechar, frear, parar, barrar e tirar de circulação a diferença da cidade.

\section{Referências}

Birman, J. (1999). Os Sentidos da Saúde. PHYSIS - Revista de Saúde Coletiva, 9(1), 7-12.

Caetano C. L.C Era uma Vez um Menininho Torto: Desajustamentos Sociais e Práticas Cotidianas. Monografia de Especialização, em Clínica e Saúde (não publicada), URI- Universidade Regional do Alto Uruguai e das Missões, Campus Santiago.

Caetano C.L.C \& Scisleski A.C. C. (2011). Era uma Vez um Menininho Torto: Desajustamentos Sociais e Práticas Cotidianas. Revista Polis e Psique, 1(2), 119-144.

Camargo C.M.E (1991) O Acompanhamento Terapêutico e a Clinica: A Função do Acompanhante Terapêutico no Tratamento. In Equipe de Acompanhantes Terapêuticos do Hospital Dia A Casa (orgs.). A rua como espaço clínico. Acompanhamento Terapêutico. (pp. 67-78) São Paulo: Escuta.

Faleiros, V. P. (2009). Infância e processo político no Brasil. In I. Rizzini, \& F. Pilotti. (orgs.). A arte de governar crianças: a história das políticas sociais, da legislação e da assistência à infância no Brasil. (pp.33-96) São Paulo: Cortez.
Foucault, M. (2000). Em defesa da sociedade: Curso no Collège de France (1975-1976). (M. E. Galvão, trad.) São Paulo: Martins Fontes.

Foucault, M. (2001). Os Anormais: Curso no Collège de France (1974-1975). (E. Brandão trad.) São Paulo: Martins Fontes.

Foucault, M. (2007). Microfísica do Poder. 23a. ed. Rio de Janeiro: Graal.

Goffman, E. (1988) Estigma: notas sobre a manipulação da identidade deteriorada. (M. B. M. L. Nunes, trad.) Rio de Janeiro: Guanabara.

Goffman, E. (2001). Manicômios, Prisões e Conventos. (D. M. Leite trad.) São Paulo: Perspectiva.

Guareschi N \& Pelliccioli E. C. (2004). Problematizando o acompanhamento terapêutico e formas de trabalhar na rede pública de saúde. In C. A. T. Nascimento et al. (orgs). Psicologia e Políticas públicas: experiências em Saúde Pública (pp. 108-119). Porto Alegre: CRP - 7ª. Região.

Iamin S.R.S. \& Ramos L.H. (2013) Sobre o Dispositivo Clinico de Intervenção do Acompanhamento Terapêutico. In S. R. S. Iamin. (Org.) Manual de Acompanhamento Terapêutico: Contribuições Teóricas e Práticas para a Aplicabilidade Clínica. (pp. 3-10). São Paulo: Livraria Santos.

Lei Federal Nº 8.069 de 1990. (1990). Estatuto da Criança e do Adolescente. Dispõe sobre o Estatuto da Criança e do Adolescente e dá outras providências. Brasíli, DF

Mauer, S. K. \& Resnizky, S. (1987). Acompanhantes terapêuticos e pacientes psicóticos: manual introdutório de uma estratégia clinica. (W. P. Rosa, trad.). Campinas: Papirus.

Onocko R.T. C e Campos, G. W. S (2006). Co-Construção de autonomia: O Sujeito em Questão Campos, in Tratado de saúde coletiva. São Paulo: Hucitec.

Palombini, A.L. (2006). Acompanhamento terapêutico: dispositivo clínico-político. Revista Psychê, 10(18), 115-127.

Palombini, A.L. (Org.) (2008.) Acompanhamento terapêutico na rede pública: a clínica em movimento. 2. ed. Porto Alegre: UFRGS.

Porto M. \& Sereno D. (1991). Sobre o Acompanhamento Terapêutico. In Equipe de Acompanhantes Terapêuticos do Hospital-Dia A Casa (orgs.) (1991). A rua como espaço clínico: Acompanhamento Terapêutico. (pp. 23-30) São Paulo: Escuta. 
Pereira, W C C. (2001) Nas trilhas do trabalho comunitário e social: teoria, método e prática. Belo Horizonte: PUC Minas.

Scisleski, A. (2010). Patologia e exclusão? As relações entre saúde e justiça, no atendimento de jovens em conflito com a lei. In Psicologia, Formação, Políticas e Produção de Saúde (Orgs.) Guareschi N. \& Cruz, R. C (pp.289-298), Porto Alegre: ediPUCRS.
Scisleski, A; Maraschin, C; Silva, R. N. (2008). Manicômios em Circuito: o percurso dos jovens e a internação psiquiátrica. Cadernos de Saúde Pública, 24(2), 342-352.

Psicol. Argum. 2014, 32(79), Supl. 2, 89-97 